\title{
Adjustment of Secondary School Students in Relation to their Gender
}

\author{
Mahesh D. Makwana*, Dr. S. M. Kaji**
}

\section{ABSTRACT:}

The present investigation in to find out the Adjustment of Secondary School Students in Relation to their gender boys and girls. The sample consisted of 120 secondary school students out of which 60 where boys and 60 where girls. For this purpose of investigation "Adjustment Inventory" by Dr.R.S.Patel was used. The obtained data were analyzed through ' $\mathrm{t}$ ' test to know the mean difference between secondary school students in relation to their gender. The result shows that there is no significant difference in Home, School and Emotional adjustment of boys and girls secondary school student. But there is significant difference in Social adjustment of boys \& girls secondary school students at 0.05 level. It means boys are Social adjustment better than girls.

\section{Keywords: Adjustment, Student, Boys, Girls}

\section{INTRODUCTION}

Adjustment is a popular expression used by people in day to day life. For example, while traveling in a - bus Or a train, we often hear or use this term; even when a guest comes to stay with us for a few days we have to adjust him/her in our house. Though sometimes we face problems in making these adjustments, they are important to maintain personal as well as social peace and harmony. Adjustment can be viewed from two angles. Firstly, adjustment may be viewed as an achievement or how well a person handles his conflicts and overcomes the resulting tension. Secondly, adjustment may be looked upon as a process as to how a person adjusts or compromises to his conflicts. Thus adjustment maintains peace and harmony in home, school, and society and in the country. So Adjustment can be defined as a psychological process. It frequently involves coping with new standards and values. In the technical language of psychology, getting along with the members of the society as best as one can is called adjustment. The present study is an effort in that direction it aims at studying some schools students' related variables as they can serve predictor variables of school adjustment.

\footnotetext{
* Ph.D.Scholar, Psychology, Gujarat University, Ahmadabad, Gujarat

**Associate Professor, Department of psychology, L.D. Arts College, Ahmedabad -Gujarat
}

(C) 2014 M Makvana, S Kaji; licensee IJIP. This is an Open Access Research distributed under the terms of the Creative Commons Attribution License (http://creativecommons.org/licenses/by/2.0), which permits unrestricted use, distribution, and reproduction in any Medium, provided the original work is properly cited. 
Sharma (1995) conducted a study to identify the over and under achievers and comparing them with regard to adjustment in school, social and home area and found that there was significant difference among over, average and under achievers with regard to their adjustment in school, home, social, religious and miscellaneous area; the over achievers had better adjustment than the under achiever in all these areas of adjustment; those who had more effective adjustment in school, home, social, religion, and miscellaneous areas were over achievers and those having less effective adjustment in these areas were under achievers.

Kasinath (2003) studied interactive effect of mental health, school adjustment and socio economic status on academic achievement with the objective to find out the difference among students who were well adjusted and mal-adjusted to school environment differ in their academic achievement by taking a sample of 200 students (102 boys and 98 girls) with the age range of 1516 years and found that mental health had significant determinant effect on achievement in school subjects; students having better social and emotional adjustment attain good academic scores.

Bookman (1996) studied academic adjustment in relation to scholastic achievement of secondary school pupils by taking a sample of 545 senior secondary school students and found that academic adjustment was significantly related to the scholastic performance; the scholastic performance and locality were unrelated; there was no difference among the subjects from urban, semi-urban and rural localities with regard to scholastic performance.

Singh (2010) studied mental health in relation to spiritual intelligence, altruism, school environment and academic achievement of senior secondary students and found that male students had significantly higher level of academic achievement than female students; students residing in urban area had significantly higher academic achievement than students residing in rural area; academic achievement of students studying in aided schools was significantly higher than students studying in government schools; academic achievement of students studying in unaided schools was significantly higher than students studying in government school; academic achievement of students studying in aided schools was significantly higher than students studying in unaided schools.

Thakkar (2003) studied academic achievement, adjustment and study habits of rural and urban students and found that there was no significant relationship in academic achievement and study habits for rural and urban students; there was positive significant difference between rural and urban students in adjustment areas of home, family, emotional and total but in the areas of social and educational adjustment the difference was not significant; there was no significant correlation between academic achievement and adjustment among rural and urban locality; a positive significant difference between low and high achieving students in the areas of home and family, personal and emotional, education, health and total adjustment; in social adjustment there was no significant difference between low and high achieving groups. On the urban locality, there was no significant difference between low achieving and high achieving students in all the five dimensions of adjustment; there was no significant difference between rural and urban boys 
with regards to academic achievement; adjustment pattern showed that urban boys were slightly better adjusted than their rural counter parts in the areas of home, family, personal, emotional and health adjustment; rural boys were slightly better adjusted in comparison to the urban students in the area of social adjustment; significant difference was observed between rural boys and urban boys in the areas of home, family, personal, emotional and health adjustment.

Singh (2006) studied the effect of socio-emotional climate of school on the adjustment of students and found that social climate of the school affects the emotional and total adjustment of students significantly; boys had significantly better health and emotional adjustment than girls whereas girls were significantly better in school adjustment than boys; girls were significantly better than boys in home and school adjustment at different levels of emotional climate of the school whereas boys were significantly better in emotional and health adjustment; social and emotional climate of the school and gender do not interact significantly with regard to home, health, social, school, emotional and total adjustment of students.

JdaitawiM.T. et al (2011), Department of Counseling and Psychology, College of Arts and Science University Utara Malaysia, Emotional Intelligence in Modifying Social and Academic Adjustment among First Year University Students in North Jordan. The present study examines the influence of emotional intelligence training in increasing social and academic adjustment among first year university students in North Jordan. A total number of 289 first year university students who were randomly selected from the two universities in North Jordan comprised both the experimental and control group. The results of the study indicate significant mean differences between the two groups having emotional intelligence as a variable. Additionally, the results indicate no significant differences between experimental and control group on social and academic adjustment variables. Supported by no significant mean difference according to gender between participants but the results indicate significant mean differences according to age between them. Although the descriptive statistics results show no significant differences as expected; the experimental group is revealed to be more effective with participants in all the research variables. Therefore, it is recommended that emotional intelligence training should be utilized as adjunct strategy in enhancing student social and academic adjustment among adolescents and adult students.

\section{Objective of the study:}

The main objectives of the study were as under:

The purpose of the present study is the difference related to the home, school, social and Emotional adjustment of secondary school students in relation to their gender. 


\section{Hypothesis:}

1. There is no significant difference between home adjustments of secondary school students in relation to their gender.

2. There is no significant difference between school adjustments of secondary school students in relation to their gender.

3. There is no significant difference between social adjustments of secondary school students in relation to their gender.

4. There is no significant difference between emotional adjustments of secondary school students in relation to their gender.

\section{METHOD:}

\section{Sample:}

The present study was carried out on secondary school students of Ahmedabad District Gujarat Elements of the study are 120 secondary school students out of which 60 were boys and 60 were girls' secondary school students.

Tool:

In the present investigation measure the Adjustment "Adjustment Inventory" by Dr. R.S. Patel (1998) was used. The adjustment inventory consists 60 items with yes/ impartial /no response pattern. 15 were home, 15 were School, 15 Social \& 15 were Emotional Adjustment Items. The reliability factor is Split Half 0.88 and test-retest $0.69 \&$ Validity is 0.70 .

Procedure:

The boys and Girls who were studying in Secondary School of different areas in Ahmedabad District, were randomly selected \& Dr. R. S. Patel 'Adjustment Inventory' was give \& data was collected. The obtain data form 120 boys and girls were analyzed with the help of mean, $\mathrm{SD}$ and ' $\mathrm{t}$ ' test.

\section{RESULTS \& DISCUSSION:}

The main objective of present study was to do study of Adjustment of The secondary school students among boys and girls. In it statistical' method was used and their correlation was measured. Results discussions of present study are as under: 
Table No: 1, Showing the Mean, SD and ' $t$ ' value of home adjustment of secondary school students among boys and girls.

\begin{tabular}{lccccccc}
\hline Variable & No. & Mean & SD & $\begin{array}{c}\text { Mean } \\
\text { diff }\end{array}$ & SED & ' $t$ ' & Sig \\
\hline Boys & 60 & 11.03 & 2.47 & 0.08 & 0.43 & 0.195 & NS \\
Girls & 60 & 10.95 & 2.20 & & & & \\
\hline
\end{tabular}

Non significant at 0.05 level.

The above result table No. 1 we can see that ' $t$ ' test was used to know the level of home adjustment secondary school students among boys and girls. where boys mean was 11.03 \& SD was 2.47 and girls mean was $10.95 \&$ SD was 2.20 and difference between their ' $t$ ' values was 0.195 it was no significance at 0.05 level. The result shows that there is no significant mean difference home Adjustment of Secondary School Student in boys and girls. Thus the null hypothesis, I which states " There is no significant difference in the home adjustment level of secondary school students with respects to their home adjustment "no difference between boys and girls.

Table No: 2, Showing the Mean, SD and 't' value of school adjustment of secondary school students among boys and girls.

\begin{tabular}{lccccccc}
\hline & & \multicolumn{7}{c}{ Mean } & & \\
Variable & No. & Mean & SD & diff & SED & 't' & Sig \\
\hline Boys & 60 & 10.03 & 2.56 & 0.15 & 0.48 & 0.311 & NS \\
Girls & 60 & 10.18 & 2.73 & & & & \\
\hline
\end{tabular}

Non significant at 0.05 level.

The above result table No.2 we can see that ' $t$ ' test was used to know the level of school adjustment secondary school students among boys and girls. where boys mean was $10.03 \&$ SD was 2.56 and girls mean was $10.18 \&$ SD was 2.73 and difference between their ' $t$ ' values was 0.311 it was no significance at 0.05 level. The result shows that there is no significant mean difference school adjustment of secondary school student in boys and girls. Thus the null hypothesis, I which states "there is no significant difference in the school adjustment level of secondary school students with respects to their school adjustment" no difference between boys and girls. 
Table No: 3, Showing the Mean, SD and ' $t$ ' value of social adjustment of secondary school students among boys and girls.

\begin{tabular}{lccccccc}
\hline & & \multicolumn{5}{c}{ Mean } \\
Variable & No. & Mean & SD & diff & SED & 't' & Sig \\
\hline Boys & 60 & 11.75 & 2.10 & 0.82 & 0.39 & 2.11 & Sig \\
Girls & 60 & 10.93 & 2.14 & & & & \\
\hline
\end{tabular}

Significant at 0.05 level.

The above result table No.3 we can see that ' $t$ ' test was used to know the level of social adjustment secondary school students among boys and girls. where boys mean was $11.75 \&$ SD was 2.10 and girls mean was $10.93 \&$ SD was 2.14 and difference between their ' $t$ ' values was 2.11 it was significance at 0.05 level. Thus the null hypothesis, I which states "there is significant difference in the social adjustment level of secondary school student with respects to their social adjustment. Here null hypothesis was rejected and result shows that the social adjustment is high level of boys more than the girls.

Table No: 4, Showing the Mean, SD and 't' value of Emotional adjustment of secondary school students among boys and girls.

\begin{tabular}{lccccccc}
\hline & & \multicolumn{5}{c}{ Mean } \\
Variable & No. & Mean & SD & diff & SED & 't' & Sig \\
\hline Boys & 60 & 9.60 & 2.58 & 0.61 & 0.43 & 1.42 & NS \\
Girls & 60 & 8.98 & 2.16 & & & & \\
\hline
\end{tabular}

Non significant at 0.05 level.

The above result table No.4 we can see that ' $t$ ' test was used to know the level of Emotional Adjustment secondary school students among boys and girls. where boys mean was $9.60 \&$ SD was 2.58 and girls mean was $8.98 \&$ SD was 2.16 and difference between their ' $t$ ' values was 1.42 it was no significance at 0.05 level. The result shows that there is no significant mean difference school adjustment of secondary school student in boys and girls. Thus the null hypothesis, I which states "there is no significant difference in the emotional adjustment level of secondary school students with respects to their emotional adjustment" no difference between boys and girls.

\section{CONCLUSION :}

We can conclude by data analysis as follows:

1. There is no significant mean difference in home adjustment of secondary school students in relation to their gender.

2. There is no significant mean difference in school adjustment of secondary school students in relation to their gender 
3. There is a significant mean difference in social adjustment of secondary school students in relation to their gender. boys students adjustment is more than girls.

4. There is no significant mean difference in emotional adjustment of secondary school students in relation to their gender.

\section{REFERENCES:}

1. Adesoji, A. Oni (2010), “ Peer group pressure as a department of adolescent social adjustment in Nigerian schools "Department of Educational Foundations, Faculty of Education, University of Lagos, Akoka-Yaba, Lagos, Nigeria, Asian Pacific Journal of Educators and Education, Vol. 25, 189-202, 2010.

2. Adler, F. (1960) .The Value Concept in Sociology. American Journal of Sociology, 65, 344-356..

3. Bhatnagar, I. (1984). A Study of Some Family Characteristics as Related to Secondary School Students' Activism, Values, Adjustment and School Learning. Ph.D. Education. In Buch, M.B. (Ed.): Fourth Survey of Research in Education, New Delhi: NCERT

4. Bhatia, K.T. (1984) .The Emotional, Personal and Social Problems of Adjustment of Adolescents under Indian Conditions with Special Reference to Values of Life. Ph.D. Education, Bombay University, In Buch, M.B. (Ed.): Fourth Survey of Research in Education,(p.347),NewDelhi: N.C.E.R.T

5. Crow, L.D. (1967) .Psychology of Human Adjustment. (3rd ed.), New York: Alford K. Knoff.

6. Chopra, R., and Kalita, R. (2006) .Adjustment Problems of Elementary School Children of Single-Parent and Intact Parent Families.Edutracks, Neelkamal Publication (P) Ltd., $36-40$

7. Jaikumar, S. and R. Muthumanickam (2010), "Social adjustment of higher secondary school students” Department of Education, Annamalai University, Annamalai Nagar, Tamil Nadu, India.

8. Jain, P. and Jandu, K. (1998).A Comparative Study of School Adjustment of Adolescent Girls and Boys of Employed and Non-Employed Mothers in Age Group 14-18 years. Journal of Education Research and Extension. 35(2), 14-21.

9. Malek, T. Jdaitawi and other (2011), Emotional Intelligence in Modifying Social and Academic Adjustment among First Year University Students in North Jordan. Department of Counseling and Psychology, College of Arts and Science University Utara Malaysia,

10. Narad, A. (2007). A Study of Personal Values of Senior Secondary School Students in Relation to School Environment and Home Environment, Unpublished Ph.D. Thesis in Education. Chandigarh: Punjab University

11. Orit Bart and others, (2007), "Predicting School Adjustment from Motor Abilities in Kindergarten ”. DepartmentofOccupationalTherapy,Tel-AvivUniversity, Israel,

12. Patel, R.S. (1998). 'Adjustment Inventory'. AkashManomapan Kendra, Ahmedabad, Gujarat, India. 
13. Shaffer and Shoben, (1961). "The Psychology of Adjustment"( 2nd ed.), .Boston : Houghton Mifflin.

14. Shukla, S.S. (2013/14, $2^{\text {nd }}$ Edition) Educational Psychology.Agrawal Publications, Agra, India. 